\title{
A cost management model for hospital food and nutrition in a public hospital
}

\author{
Liliana Neriz ${ }^{1}$ Alicia Núñez ${ }^{1 *}$ and Francisco Ramis ${ }^{2}$
}

\begin{abstract}
Background: In Chile, the use of costing systems in the public sector is limited. The Ministry of Health requires hospitals to manage themselves with the aim of decentralizing health care services and increasing their quality. However, self-management with a lack of accounting information is almost impossible. On the other hand, nutrition department costs have barely been studied before, and there are no studies specifically for activity based costing (ABC) systems. $A B C$ focuses on the process and traces health care activities to gain a more accurate measurement of the object costs and the financial performance of an organization.

Method: This paper uses ABC in a nutrition unit of a public hospital of high complexity to determine costs associated with the different meals for inpatients. The paper also provides an activity based management (ABM) analysis for this unit.

Results: The results show positive effects on the reduction of costs for the nutrition department after implementing $A B C / A B M$. Therefore, there are opportunities to improve the profitability of the area and the results could also be replicated to other areas in the hospital. ABC shed light on the amount of nutritionist time devoted to completing paperwork, and as a result, system changes were introduced to reduce this burden and allow them to focus on more relevant activities. Additional efficiencies were achieved through the elimination of non-value adding activities and automation of reports. ABC reduced the cost of the nutrition department and could produce similar results in other areas of the hospital.
\end{abstract}

Conclusions: This is a practical application of a financial management tool, ABC, which would be useful for hospital managers to reduce costs and improve the management of the unit. This paper takes $A B C$ and examines its use in an area, which has had little exposure to the benefits of this tool.

Keywords: Activity based costing, Diet costs, Nutrition costs, Activity based management for nutrition units

\section{Background}

Improving nutritional status in any country is a challenge. It has been well documented that poor people are at increased risk for specific health conditions and diseases given their financial situation, lack of education, poor nutrition and health status [1]. In this way, nutrition is a factor in exacerbating inequalities in health. Hospitals also have an important nutritional role in preventing illness and maintaining the health of their patients; this produces a constant need to improve their efficiency and productivity. However, achieving hospital efficiency is not easy, particularly nowadays when there

\footnotetext{
* Correspondence: anunez@fen.uchile.cl

'Department of Management Control and Information Systems, School of Economics and Business, Universidad de Chile, Santiago, Chile

Full list of author information is available at the end of the article
}

are many hospitals suffering from the absence of administrative and financial autonomy, and also have budgets that ignore the actual services provided by them [2].

Thus, nutrition is an important determinant of health for any patient. Adequate patient meals are an essential part of hospital treatment and the consumption of a balanced diet is crucial for a patient's recovery. Although diet is just one of the lifestyle factors that influences quality of life, a proper diet combined with aftercare and nutritional education may influence the quality of the patient's future health and life. The importance of hospital food and its benefits have been well studied [3,4]. However, the provision of hospital meals is a difficult process aggravated by the potential of the patient's malnutrition $[5,6]$.

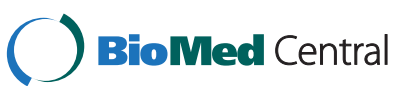

(c) 2014 Neriz et al.; licensee BioMed Central Ltd. This is an Open Access article distributed under the terms of the Creative Commons Attribution License (http://creativecommons.org/licenses/by/4.0), which permits unrestricted use, distribution, and reproduction in any medium, provided the original work is properly credited. The Creative Commons Public Domain Dedication waiver (http://creativecommons.org/publicdomain/zero/1.0/) applies to the data made available in this article unless otherwise stated. 
People tend to forget the importance of hospital food services when comparing other clinical activities, and meal services are more prone to be subject to a budgetary cut than other services [7]. Therefore, it is difficult to find the balance between delivering quality food services and appropriate costs, mainly because of the lack of competencies required to perform this task and tools to enable proper management of the services. In addition, the quality of hospital food services has a critical effect on patient satisfaction [8], which influences the patient's perception of the quality of the services provided by the hospital. The potential impact on both health status and patient satisfaction emphasizes the need to achieve quality in the food and nutritional services provided, which is not independent of the decision of how to allocate limited resources.

In any hospital it is a challenge to control health care expenses. In fact, escalating health care costs due to changes in the age distribution of the population increases in the levels of expectation for health care services, and the application of new technologies for health care delivery urge governments towards cost containment solutions. As a result, there is a need for more accurate data on health care services costs, which is useful for policy making as well as internal management decisions [9-11].

In view of producing more accurate cost estimates, health care organizations have started to invest in sophisticated management tools, including costing systems. ABC is a cost accounting system, which: (i) allows cost efficiency without negative impact on the quality of services, (ii) provides information for management, and (iii) and aids with continuous quality improvements [12]. ABC allocates indirect costs to services using a multistep allocation procedure on the basis of activity consumption. Based on the information provided by $\mathrm{ABC}$, there is a set of actions and improvements that can be performed in a process to satisfy customers and reduce or control costs, known as ABM [13].

In Chile, there is a lack of health care cost accounting systems for decision-making processes in public hospitals, including nutrition units. There are many benefits associated with the use of more sophisticated techniques, for example, Álvarez et al. have shown that improving the quality of information systems in clinical nutrition will have a positive impact on the overall results of the hospital when measured in terms of effectiveness, efficacy or quality [14].

The aim of this study is to describe the development and application of $\mathrm{ABC}$ and $\mathrm{ABM}$ systems for a nutrition department in a hospital of high complexity.

\section{Activity based costing}

$\mathrm{ABC}$ is an information system that not only maintains and processes data on activities and services to allocate costs, but also supports management decision-making. $\mathrm{ABM}$ describes the decision-making process that uses the information provided by $\mathrm{ABC}$ to comply with the objectives of any organization. According to Kaplan and Cooper [13], ABC helps managers by: defining prices of products/services, reducing costs by improving processes, focusing on quality and security, eliminating activities that do not add value and performing benchmarking.

$\mathrm{ABC}$ focuses on the processes and activities that take place in an organization. Indirect costs are accumulated for each activity as a separate cost object and then applied to products or services. There is extensive literature about studies and applications of $\mathrm{ABC}$ in North America and Europe, but not in Latin America. To mention a few: Barros et al. [15], Ross [16], Udpa [17], Laurila et al. [18], Roybal et al. [19], Dodson et al. [20], Canby [21] and Car [22]. All these authors present evidence of benefits associated with the implementation of ABM in health care organizations.

For nutrition units, ABC can play an essential role in maximizing reimbursement revenues and lowering operational costs without compromising the quality of the services. The importance of delivering high-quality nutritional care for patients at risk of malnutrition and its effects on clinical outcomes and costs savings has been well documented by Smith and Smith [23]. There are many studies that present experiences in nutrition units using cost-benefit and cost-effectiveness analysis such as Hedberg et al. [24], Brugler and Berstain [25], among others.

A paper presented by Pereira [26] examines costmanagement methods in a Brazilian nutrition and diet unit. The authors compare the weight calculation costing method with the absorption costing method showing great discrepancies between these two methodologies. The authors suggest the adoption of more accurate methodologies to assign costs, such as ABC. Despite Pereira's work, $\mathrm{ABC} / \mathrm{ABM}$ for nutrition units has not been widely discussed in the literature.

\section{Methods}

$\mathrm{ABC}$ involves a two-step process: the first step traces resources costs to activities, followed by a second step that traces activities costs to products or services to determine their cost. This paper adopts the methodology suggested by Kaplan and Cooper [13], which has been previously implemented by Canby [21] and Roybal et al. [19], to name a couple. The methodology consists of: first, thoroughly analyze the organization processes; second, identify and classify activities associated to the processes; third, identify resource drivers to assign indirect costs to activities; and fourth, assign activity costs to cost objects through the use of activity drivers. 


\section{Organization process analysis}

To understand the processes involved in the nutrition department, three information sources were considered: interviews with key personnel, observation of the different tasks performed in the unit, and measurement of process time.

\section{Activity analysis}

Once the different processes are recognized, activity analysis within $\mathrm{ABC}$ evaluates resource consumption though the identification of activities. Activity analysis provides information such as what task is done, how it is done, and time necessary to perform the task. Activity data was collected through observation and interviews, and gathering data from existing documents and records. As a result, 24 nutritional activities were identified in five major areas.

\section{Cost drivers}

Resource drivers and activity drivers were collected based on cause-and-effect relationships between activities and resources, and between activities and cost objects, respectively.

\section{Cost objects}

Cost objects for the nutrition unit were understood as the result of the production process with an economic sense. In this study the cost objects correspond to the different clinician diets that are recommended for each patient. In this study 36 types of diets are provided by the hospital.

In summary, $\mathrm{ABC}$ uses resource drivers to assign indirect costs to activities, and then the costs of activities are assigned to cost objects (diets) based on the appropriate activity driver. See Figure 1.

\section{Data sources}

$\mathrm{ABC}$ methodology was applied and information was obtained from the Guillermo Grant Benavente Hospital in Concepción, Chile, which is a hospital of high complexity, for all ages, with a capacity of 927 beds. The data presented in the ABC model is from January-December 2005 when the model was first implemented. During 2005, the hospital had a total of 40,466 patient discharges, an average of 725 hospitalized patients per day, and approximately 2,260 meals were prepared per day. This model has been updated in the hospital to date.

\section{Ethical approval and data protection}

For the course of this study a confidential agreement was settled between the University of Chile, the Guillermo Grant Benavente Hospital, and FONDEF. The study design was approved by the ethics committee from the Faculty of Economics and Business of the University of Chile.

\section{Consent}

Consent from the patient was not required, as this study reports an assessment of the hospital costs not at the patient level.

\section{Results}

This section details the development and implementation of $\mathrm{ABC}$ in the nutrition department of a hospital of high complexity in Chile. A key for this case study was the willingness of the nutrition unit to provide access to all relevant information. We have divided this section into four steps: in the first step, we explain the processes involved in the nutrition department; second, we present an activity analysis for each relevant activity performed by the nutrition unit. In a third step, we calculate the cost of the different activities; and fourth, we calculate the cost of the different diets.

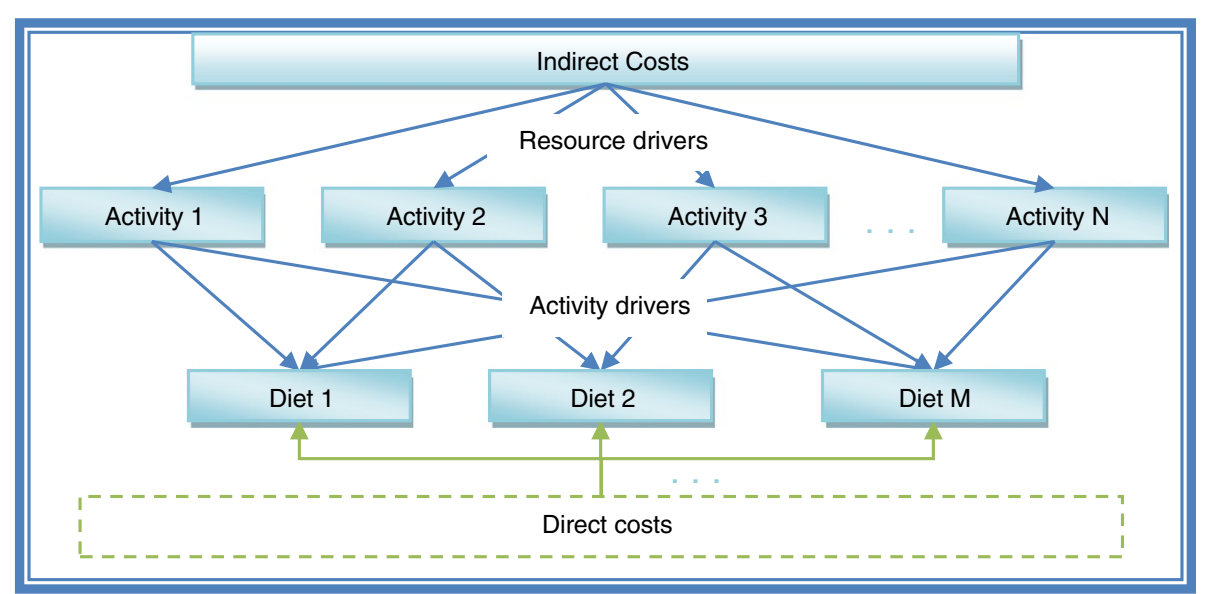

Figure $1 \mathrm{ABC}$ methodology. 


\section{Step 1: process analysis}

Process analysis provides basic information about the activities performed in the nutrition department. The main processes identified in the department are: nutritional care, planning and food production.

- Nutritional care: This process starts with the visit to the patient to identify the appropriate diet in accordance with the physician's specifications, and ends with a daily diet report specifying the number of different meals for the day. Six nutritionists, one per floor, participate in this process, which includes two visits to each patient per day.

- Planning: The planning process uses the daily diet report to calculate the ingredients required for food production and its availability for each meal. Four nutritionists and one assistant participate in this process.

- Food production: this process includes activities that range from receiving food supplies to

Table 1 Activity dictionary for the nutrition department

\begin{tabular}{|c|c|c|c|}
\hline $\mathbf{N}^{\circ}$ & Activity & Description & Type of activity \\
\hline 1 & Visit patients & Nutritionist visits the patient to assign daily diet. & Nutritional care \\
\hline 2 & Count diets & Nutritionist counts the different diets. & Planning \\
\hline 3 & Create report & Nutritionist prepares a report with the diets for the day. & Planning \\
\hline 4 & Compute ingredients & $\begin{array}{l}\text { Nutritionist counts the amount of ingredients required to order them from } \\
\text { storage and different suppliers. }\end{array}$ & Planning \\
\hline 5 & Request ingredients & $\begin{array}{l}\text { Nutritionist requests the ingredients from storage or calls suppliers to } \\
\text { check availability. }\end{array}$ & Planning \\
\hline 6 & Receive ingredients & $\begin{array}{l}\text { Assistants receive ingredients to control for quality and quantity, and then } \\
\text { store the food. }\end{array}$ & Food Production \\
\hline 7 & Control reception of ingredients & $\begin{array}{l}\text { Nutritionist verifies that the reception of ingredients is appropriate according } \\
\text { to the defined standards. }\end{array}$ & Food Production \\
\hline 8 & Prepare desserts and salads & Kitchen assistants prepare desserts and salads for the day or next day accordingly. & Food Production \\
\hline 9 & Control desserts and salad & $\begin{array}{l}\text { Nutritionist supervise that the preparation of dessert and salads is performed } \\
\text { correctly and meets the standards set by the hospital in terms of safety } \\
\text { and hygiene. }\end{array}$ & Food Production \\
\hline 10 & Prepare ingredients & Kitchen assistants wash, peel, chop, and disinfect food. & Food Production \\
\hline 11 & $\begin{array}{l}\text { Control preliminary preparation } \\
\text { of ingredients }\end{array}$ & $\begin{array}{l}\text { Nutritionist supervise that the preliminary preparation of the food is performed } \\
\text { correctly and meets the standards set by the hospital in terms of safety } \\
\text { and hygiene. }\end{array}$ & Food Production \\
\hline 12 & Prepare Food & Kitchen assistants cook the food for the different meals. & Food production \\
\hline 13 & Control food preparation & $\begin{array}{l}\text { Nutritionist supervise that the food is prepared correctly and meets the standards } \\
\text { set by the hospital in terms of safety and hygiene. }\end{array}$ & Food Production \\
\hline 14 & Prepare trays & Kitchen assistants prepare patients' trays for the different meals. & Food production \\
\hline 15 & Control preparation of the trays & Nutritionist reads the daily diet report to load the trays accordingly. & Food Production \\
\hline 16 & Distribute to patients & Assistants distribute the food to the patients. & Food Production \\
\hline 17 & Nutritional control & Nutritionists verify that the diet plan correspond to the patient. & Nutritional care \\
\hline 18 & Remove trays & Assistants remove trays from the patients and take them back to the kitchen. & Food Production \\
\hline 19 & Wash trays & $\begin{array}{l}\text { Kitchen assistants wash and put away the trays according to the standards set by } \\
\text { the hospital in terms of safety and hygiene. }\end{array}$ & Food Production \\
\hline 20 & Wash cooking implements & $\begin{array}{l}\text { Kitchen assistants wash and put away cooking implements such as containers, } \\
\text { pots, pans, etc. according to the standards set by the hospital in terms of safety } \\
\text { and hygiene. }\end{array}$ & Food Production \\
\hline 21 & Wash control & $\begin{array}{l}\text { Nutritionist supervises that the washing and putting away activities of the trays } \\
\text { and cooking implements is performed correctly and meets the standards set by } \\
\text { the hospital in terms of safety and hygiene. }\end{array}$ & Food Production \\
\hline 22 & Clean area & $\begin{array}{l}\text { Assistant cleans the kitchen and office area according to the standards set by the } \\
\text { hospital in terms of safety and hygiene. }\end{array}$ & Food Production \\
\hline 23 & Remove garbage & Assistant removes garbage. & Food Production \\
\hline 24 & Coordinate nutrition department & $\begin{array}{l}\text { General coordination activities that involve organization of shifts, budgetary } \\
\text { control, alignment with other areas, etc. }\end{array}$ & Planning \\
\hline
\end{tabular}


preparing the food, to hygiene. 24 kitchen assistants and 3 nutritionists participate in this process.

\section{Step 2: activity analysis}

An activity dictionary was constructed for a typical nutrition unit based on: the process analysis, several interviews, direct observation and time measurements. We identified 24 activities classified into 5 categories: (i) nutritional care activities, (ii) administrative activities, (iii) food production activities, (iv) supervision, (v) distribution and hygiene activities. Table 1 shows the activity dictionary.

We removed some activities from the original activity dictionary, which includes activities related to the provision of food for the workers of the hospital because they are not the core of the hospital and the subject matter for this study.

\section{Step 3: activity costs}

In order to determine the costs of the 24 activities previously identified, and following the $\mathrm{ABC}$ model illustrated in Figure 1, we assigned the cost of the resources to the activities using resource drivers. Table 2 shows indirect costs and resource drivers.

We use equation 1 to calculate activity costs:

$$
\begin{aligned}
\text { Activity cost } & =\sum_{i=1}^{n} \% \text { Resource }_{i} \times \text { Resource }_{i} \text { Cost } ; \\
i & =1 \ldots n \text { resources }
\end{aligned}
$$

Table 2 Indirect costs and resource drivers

\begin{tabular}{llll}
\hline $\mathbf{N}^{\circ}$ & Resources & Resource driver & $\begin{array}{l}\text { Cost (US\$ } \\
\text { per } \text { month) }\end{array}$ \\
\hline 1 & Nutritionists salaries & Labor hours & $\$ 101,188$ \\
2 & Clinical nutritionists salaries & Percentage of use & $\$ 125,516$ \\
3 & Assistants salaries & Percentage of use & $\$ 295,205$ \\
4 & Secretary salary & Square meters & $\$ 5,303$ \\
5 & Cleaning supplies & Square meters & $\$ 25,032$ \\
6 & Library supplies & Square meters & $\$ 1,119$ \\
7 & Water & Square meters & $\$ 7,952$ \\
8 & Steam boiler & Minutes of use & $\$ 40,781$ \\
9 & Gas & Activity duration & $\$ 810$ \\
10 & Electricity & Activity duration & $\$ 13,173$ \\
11 & Telephone & Activity duration & $\$ 1,027$ \\
12 & Equipment depreciation & Depreciation & $\$ 22,975$ \\
13 & Furniture depreciation & Activity duration & $\$ 3,195$ \\
14 & Rooms depreciation & Activity duration & $\$ 11,524$ \\
15 & Equipment maintenance & Activity duration & $\$ 6,713$ \\
16 & Garbage & Kilos & $\$ 6,573$ \\
\hline
\end{tabular}

Note: The Chilean peso is the currency in Chile. Conversion rate: CLP/USD $=\$ 502$ (January 2014).

Source: Own elaboration.
Equation 1 shows that activity costs correspond to the proportion of resources used by each activity multiplied by the cost of the resources. Table 3 presents activity costs for our case study.

The difference between the total indirect cost and the total activity cost comes from eliminating the activities of feeding hospital employees.

\section{Step 4: diet costs}

An inpatient receives four meals during the day: breakfast, lunch, snack break, and dinner. Some of the most recurrent diets in the hospital are: liquid diet, porridge diet, soft-food diet, no-residue soft diet, low-fat diet, and full diet. This hospital elaborates 36 different diets that we have organized into 16 different groups [27].

Group 1: common, no-restriction, full diet.

Group 2: Soft-food diet, no-salt soft-food diet, low-fat diet.

\begin{tabular}{|c|c|c|}
\hline $\mathbf{N}^{\circ}$ & Activity & $\begin{array}{l}\text { Cost (US\$ } \\
\text { per month) }\end{array}$ \\
\hline 1 & Visit patients & $\$ 60,780$ \\
\hline 2 & Count diets & $\$ 26,154$ \\
\hline 3 & Create report & $\$ 4,459$ \\
\hline 4 & Compute ingredients & $\$ 15,730$ \\
\hline 5 & Request ingredients & $\$ 1,559$ \\
\hline 6 & Receive ingredients & $\$ 40,697$ \\
\hline 7 & Control reception of ingredients & $\$ 12,146$ \\
\hline 8 & Prepare desserts and salads & $\$ 30,849$ \\
\hline 9 & Control desserts and salad & $\$ 13,348$ \\
\hline 10 & Prepare ingredients & $\$ 46,375$ \\
\hline 11 & Control preliminary preparation of ingredients & $\$ 4,207$ \\
\hline 12 & Prepare Food & $\$ 64,750$ \\
\hline 13 & Control food preparation & $\$ 4,302$ \\
\hline 14 & Prepare trays & $\$ 43,179$ \\
\hline 15 & Control preparation of the trays & $\$ 16,223$ \\
\hline 16 & Distribute to patients & $\$ 31,834$ \\
\hline 17 & Nutritional control & $\$ 19,798$ \\
\hline 18 & Remove trays & $\$ 21,367$ \\
\hline 19 & Wash trays & $\$ 58,503$ \\
\hline 20 & Wash cooking implements & $\$ 29,409$ \\
\hline 21 & Wash control & $\$ 4,211$ \\
\hline 22 & Clean area & $\$ 7,911$ \\
\hline 23 & Remove garbage & $\$ 797$ \\
\hline 24 & Coordinate nutrition department & $\$ 22,303$ \\
\hline
\end{tabular}

Table 3 Activity costs for the nutrition department

Note: The Chilean peso is the currency in Chile. Conversion rate: CLP/USD $=\$ 502$ (January 2014).

Source: Own elaboration. 
Group 3: Low-potassium soft-food diet, no-salt low-potassium soft-food diet.

Group 4: No-residue soft diet.

Group 5: Diabetic diet, no-salt diabetic diet, Giovanetti diabetic diet.

Group 6: Low potassium no-salt diabetic diet.

Group 7: No-residue diabetic diet, Low-potassium

Giovanetti diet, No-salt low-potassium Giovanetti diet.

Group 8: Carbohydrate diet, carbohydrate no-salt

diet, carbohydrate porridge, Carbohydrate no-salt

porridge.

Group 9: Porridge, no-salt porridge, no-residue

porridge, no-salt no-residue porridge, semi-liquid porridge.

Group 10: Diabetic porridge, no-salt diabetic porridge.

Group 11: No-residue diabetic porridge.

Group 12: Giovaneti diet, No-salt Giovaneti diet,

Giovanetti porridge, No-salt Giovanetti porridge.

Group 13: Low-calorie diet.

Group 14: Liquid, no-salt liquid.

Group 15: Pension.

Group 16: Adult patient breakfast, pediatric patient breakfast

The consumers of these diets correspond to patients hospitalized in the clinical services at the hospital. Therefore, the meals are carefully prepared, cover the nutritional needs of the patient, are technically planned diets and are elaborated with optimal sanitation standards of the facilities. As previously mentioned, a typical patient diet includes four meals (breakfast, lunch, snack break, and dinner), and can sometimes include additional snacks between the main dishes. In summary, the cost objects include:

- Lunch and dinner: They can vary between the groups 1 to 15 .

- Breakfast and snack break: group 16.

To determine the costs of the groups of meals, and according to the $\mathrm{ABC}$ model illustrated in Figure 1, we assigned activity costs to the group of diets using cost drivers. The cost drivers were chosen based on their causal relationship with the product, certainty and accuracy to the respective assigned costs. Table 4 shows activities, and cost drivers.

We use equation 2 to assign the costs of the activities to the different group of diets:

$$
\begin{aligned}
\text { Diet cost } & =\sum_{i=1}^{n} \% \text { Activity }_{i} \times \text { Activity }_{i} \text { Cost } ; \\
i & =1 \ldots n \text { activities }
\end{aligned}
$$

Table 5 presents the indirect costs of the groups of diets for our case study.

\begin{tabular}{|c|c|c|}
\hline $\mathbf{N}^{\circ}$ & Activity & Cost drivers \\
\hline 1 & Visit patients & Seconds per patient \\
\hline 2 & Count diets & Seconds per patient \\
\hline 3 & Create report & Labor hours \\
\hline 4 & Compute ingredients & Minutes per diet \\
\hline 5 & Request ingredients & Labor hours \\
\hline 6 & Receive ingredients & Number of meals \\
\hline 7 & Control reception of ingredients & Labor hours \\
\hline 8 & Prepare desserts and salads & Number of meals \\
\hline 9 & Control desserts and salad & Labor hours \\
\hline 10 & Prepare ingredients & Number of preparations \\
\hline 11 & $\begin{array}{l}\text { Control preliminary preparation } \\
\text { of ingredients }\end{array}$ & Labor hours \\
\hline 12 & Prepare Food & Minutes of food preparation \\
\hline 13 & Control food preparation & Labor hours \\
\hline 14 & Prepare trays & Number of meals \\
\hline 15 & Control preparation of the trays & Labor hours \\
\hline 16 & Distribute to patients & Seconds per patient \\
\hline 17 & Nutritional control & Labor hours \\
\hline 18 & Remove trays & Number of patients \\
\hline 19 & Wash trays & Number of trays \\
\hline 20 & Wash cooking implements & Number of food preparations \\
\hline 21 & Wash control & Labor hours \\
\hline 22 & Clean area & Labor hours \\
\hline 23 & Remove garbage & Number of food preparation \\
\hline 24 & Coordinate nutrition department & Labor hours \\
\hline
\end{tabular}

Table 4 Activity costs and costs drivers

Source: Own elaboration.

Table 5 shows that the number of lunches and dinners corresponds to 402,010 annual meals, and the number of breakfasts and snacks equal 745,920 meals. This difference occurs for several reasons; one of them is that on average there were 725 hospitalized patients per day, of which 193 were discharged during the day, most of the time after they have their breakfast. Also, the hospital sometimes includes additional snacks between the main dishes. And a final reason relates with the time of patient procedures and the next meal they can ingest; procedures are usually performed during the day, so patients just eat a snack or dinner later or just have breakfast the next day.

The last step to obtain the total cost per diet was to add the indirect costs with the direct costs, which are the ingredients that we are able to identify directly with the diet (examples: potatoes, carrots, etc.). The direct costs were computed for each diet; these results are shown in Table 6, and summarized in Figure 2. 
Figure 2 shows the most expensive diet is the Diabetic diet. The elevated costs are due to the high costs of the ingredients compared to the other diets.

The information provided by the $\mathrm{ABC}$ system allows us to know the cost of food for a typical inpatient in the hospital. Let's assume that we have an adult patient who has four meals and was diagnosed with a soft-food diet; the cost per day for this patient is US\$3.52, which is detailed as follows:

Breakfast $\$ 0.15$

Lunch $\$ 1.61$

Snack break $\$ 0.15$

Dinner $\$ 1.61$

Total cost per day $\$ 3.52$

Similar analyses can be conducted for all the diets and different patients. Therefore, ABC can be helpful with calculation of actual unit cost of a patient meal. All this information is now the cornerstone for the $\mathrm{ABM}$ system. An ABM system for this nutrition unit will be based on feedback from the management of the unit and the results from the accounting system. Management needs to analyze the results obtained to identify the unit's deficiencies with the aim of improving the activities that are carried out in the unit and reducing costs.

\section{Discussion}

The results provide insight into the actual costs of the patients' meals for the hospital, but they also provide valuable information about the activities carried out in the hospital. Figure 3 presents the activity costs for the whole nutrition unit. It can be appreciated that the most expensive activities are preparing food (11\%), washing and putting away trays (10\%), and visiting the patients (10\%).

This information provides nutritionists and administrators with a common language with which to discuss the link between costs and procedures, and also provides alternatives in case reduction of costs or activity improvement is required. At this point, let us provide an example of how ABM was applied for the "Visit Patients" activity implemented in this hospital, and accounted for $10 \%$ of the total costs. The nutritionists were in charge of performing this activity daily, visiting inpatients and evaluating their diets twice a day. The main activities of the clinical nutritionist should be oriented to the assessment and care of the patients, but those activities were displaced for administrative activities, which accounted for over $60 \%$ of the cost in the wages of the professionals. Nutritionists were asked to

Table 5 Diet costs

\begin{tabular}{|c|c|c|c|c|}
\hline Activity & Diet & Indirect Costs (US\$) & Number of meals & $\begin{array}{l}\text { Indirect unit costs } \\
\text { (US\$ per month) }\end{array}$ \\
\hline Group 1 & Full diet & $\$ 20,520$ & 23,708 & 0.87 \\
\hline Group 2 & Soft-food diet, no-salt soft-food diet, low-fat diet & $\$ 184,032$ & 212,630 & 0.87 \\
\hline Group 3 & $\begin{array}{l}\text { Low-potassium soft-food diet, no-salt low-potassium } \\
\text { soft-food diet }\end{array}$ & $\$ 1,495$ & 1,790 & 0.83 \\
\hline Group 4 & No-residue soft diet & $\$ 6,227$ & 7,456 & 0.84 \\
\hline Group 5 & Diabetic diet, no-salt diabetic diet, Giovanetti diabetic diet & $\$ 40,964$ & 47,866 & 0.86 \\
\hline Group 6 & Low potassium no-salt diabetic diet & $\$ 624$ & 746 & 0.84 \\
\hline Group 7 & $\begin{array}{l}\text { No-residue diabetic diet, Low-potassium Giovanetti diet, } \\
\text { No-salt low-potassium Giovanetti diet }\end{array}$ & $\$ 1,370$ & 1,642 & 0.83 \\
\hline Group 8 & $\begin{array}{l}\text { Carbohydrate diet, carbohydrate no-salt diet, carbohydrate } \\
\text { porridge, Carbohydrate no-salt porridge }\end{array}$ & $\$ 2,390$ & 2,834 & 0.84 \\
\hline Group 9 & $\begin{array}{l}\text { Porridge, no-salt porridge, no-residue porridge, no-salt } \\
\text { no-residue porridge, semi-liquid porridge }\end{array}$ & $\$ 43,157$ & 51,592 & 0.84 \\
\hline Group 10 & Diabetic porridge, no-salt diabetic porridge & $\$ 9,839$ & 11,780 & 0.84 \\
\hline Group 11 & No-residue diabetic porridge & $\$ 383$ & 448 & 0.85 \\
\hline Group 12 & $\begin{array}{l}\text { Giovaneti diet, No-salt Giovaneti diet, Giovanetti porridge, } \\
\text { No-salt Giovanetti porridge }\end{array}$ & $\$ 1,744$ & 2,090 & 0.83 \\
\hline Group 13 & Low-calorie diet & $\$ 374$ & 448 & 0.84 \\
\hline Group 14 & Liquid, no-salt liquid & $\$ 25,140$ & 29,376 & 0.86 \\
\hline Group 15 & Pension & $\$ 6,361$ & 7,604 & 0.84 \\
\hline Group 16 & Group 16: Adult patient breakfast, pediatric patient breakfast & $\$ 57,788$ & 745,920 & 0.08 \\
\hline
\end{tabular}

Note: The Chilean peso is the currency in Chile. Conversion rate: CLP/USD $=\$ 502$ (January 2014). Source: Own elaboration. 
fill out several forms indicating the patients' meals. Each nutritionist prepared a form by hand, and after they finished visiting the patients, a larger form compiling all this information was also prepared by hand. Thus, an important part of the nutritionists' day was consumed by filling out paperwork. The administration took into consideration the costs of the activities, and using a more managerial approach, came up with the solution of implementing technological tools that help nutritionists to register the diets of the different patients and avoid the use of

Table 6 Total cost by diet

\begin{tabular}{|c|c|c|c|c|c|}
\hline Diet & Group & $\begin{array}{l}\text { Number } \\
\text { of meals }\end{array}$ & $\begin{array}{l}\text { Direct unit costs } \\
\text { (US\$ per month) }\end{array}$ & $\begin{array}{l}\text { Indirect unit costs } \\
\text { (US\$ per month) }\end{array}$ & $\begin{array}{l}\text { Total unit cost } \\
\text { (US\$ per month) }\end{array}$ \\
\hline Full diet & 1 & 23,708 & 0.75 & 0.87 & 1.62 \\
\hline Soft-food diet & 2 & 141,952 & 0.75 & 0.87 & 1.61 \\
\hline No-salt soft-food diet & 2 & 54,872 & 0.75 & 0.87 & 1.61 \\
\hline Low-fat diet & 2 & 15,806 & 0.74 & 0.87 & 1.61 \\
\hline Low-potassium soft-food diet & 3 & 1,342 & 0.86 & 0.83 & 1.69 \\
\hline No-salt low-potassium soft-food diet & 3 & 448 & 0.86 & 0.83 & 1.69 \\
\hline No-residue soft diet & 4 & 7,456 & 0.56 & 0.84 & 1.40 \\
\hline Diabetic diet & 5 & 16,850 & 0.84 & 0.86 & 1.70 \\
\hline No-salt diabetic diet & 5 & 30,270 & 0.84 & 0.86 & 1.70 \\
\hline Giovanetti diabetic diet & 5 & 746 & 0.88 & 0.86 & 1.73 \\
\hline Low potassium no-salt diabetic diet & 6 & 746 & 0.97 & 0.84 & 1.81 \\
\hline No-residue diabetic diet & 7 & 746 & 0.74 & 0.83 & 1.57 \\
\hline Low-potassium Giovanetti diet & 7 & 448 & 0.71 & 0.83 & 1.54 \\
\hline No-salt low-potassium Giovanetti diet & 7 & 448 & 0.71 & 0.83 & 1.54 \\
\hline Carbohydrate diet & 8 & 1,492 & 0.40 & 0.84 & 1.24 \\
\hline Carbohydrate no-salt diet & 8 & 596 & 0.40 & 0.84 & 1.24 \\
\hline Carbohydrate porridge & 8 & 298 & 0.40 & 0.84 & 1.24 \\
\hline Carbohydrate no-salt porridge & 8 & 448 & 0.40 & 0.84 & 1.24 \\
\hline Porridge & 9 & 41,452 & 0.48 & 0.84 & 1.31 \\
\hline No-salt porridge & 9 & 8,946 & 0.48 & 0.84 & 1.31 \\
\hline No-residue porridge & 9 & 448 & 0.50 & 0.84 & 1.33 \\
\hline No-salt no-residue porridge & 9 & 448 & 0.50 & 0.84 & 1.33 \\
\hline Semi-liquid porridge & 9 & 298 & 0.45 & 0.84 & 1.28 \\
\hline Diabetic porridge & 10 & 6,412 & 0.62 & 0.84 & 1.46 \\
\hline No-salt diabetic porridge & 10 & 5,368 & 0.62 & 0.84 & 1.46 \\
\hline No-residue diabetic porridge & 11 & 448 & 0.54 & 0.85 & 1.39 \\
\hline Giovaneti diet & 12 & 448 & 0.60 & 0.83 & 1.43 \\
\hline No-salt Giovaneti diet & 12 & 746 & 0.60 & 0.83 & 1.43 \\
\hline Giovanetti porridge & 12 & 448 & 0.61 & 0.83 & 1.44 \\
\hline No-salt Giovanetti porridge & 12 & 448 & 0.61 & 0.83 & 1.44 \\
\hline Low-calorie diet & 13 & 448 & 0.56 & 0.84 & 1.40 \\
\hline Liquid diet & 14 & 28,928 & 0.09 & 0.86 & 0.95 \\
\hline No-salt liquid diet & 14 & 448 & 0.09 & 0.86 & 0.95 \\
\hline Pension & 15 & 7,604 & 0.84 & 0.84 & 1.67 \\
\hline Adult patient breakfast & 16 & 647,476 & 0.08 & 0.08 & 0.15 \\
\hline Pediatric patient breakfast & 16 & 98,444 & 0.10 & 0.08 & 0.18 \\
\hline
\end{tabular}

Note: The Chilean peso is the currency in Chile. Conversion rate: CLP/USD $=\$ 502$ (January 2014). Source: Own elaboration. 
all the paperwork (a photo of the new system is presented in Figure 4). As a result, a scarce nutritional resource was liberated to perform more relevant activities, by approximately one hour a day. The hour freed up by the nutritionists is now devoted to educating patients regarding their future diets and their impact on patient recovery and health status. Also, nutritionists now have more time to investigate new balanced diets for patients. All these activities are more relevant from a point of view of patient relapse and prevention of future diseases. Non-value-adding activities were also eliminated, such as counting diets and creating reports, as the reports are now automatically created. Finally, this leads to a reduction of costs by eliminating low-value high-cost activities and continued improvement of the unit. It is expected that $A B C$ could produce similar results in other areas of the hospital.
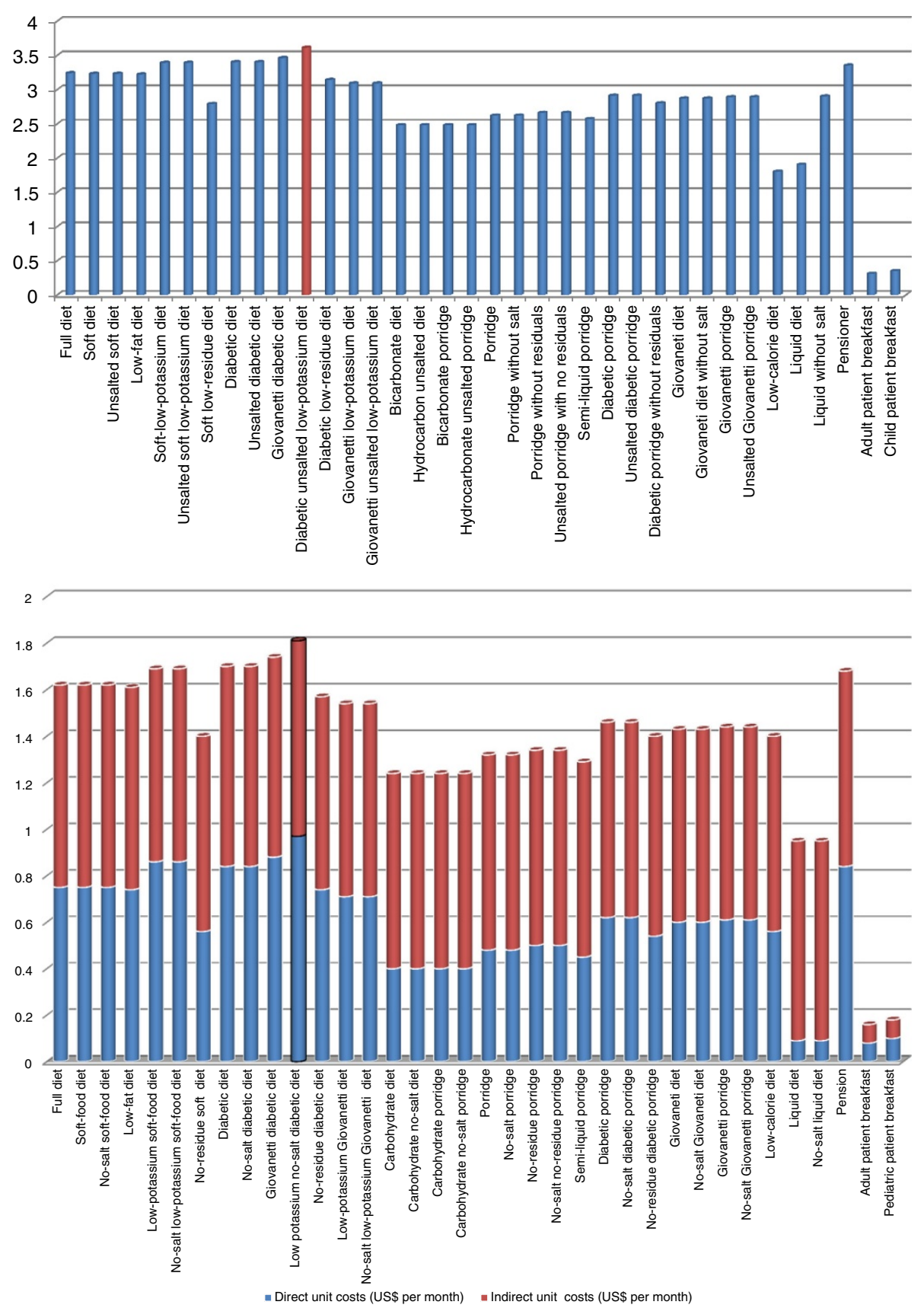

Figure 2 Total unit costs per diet. 

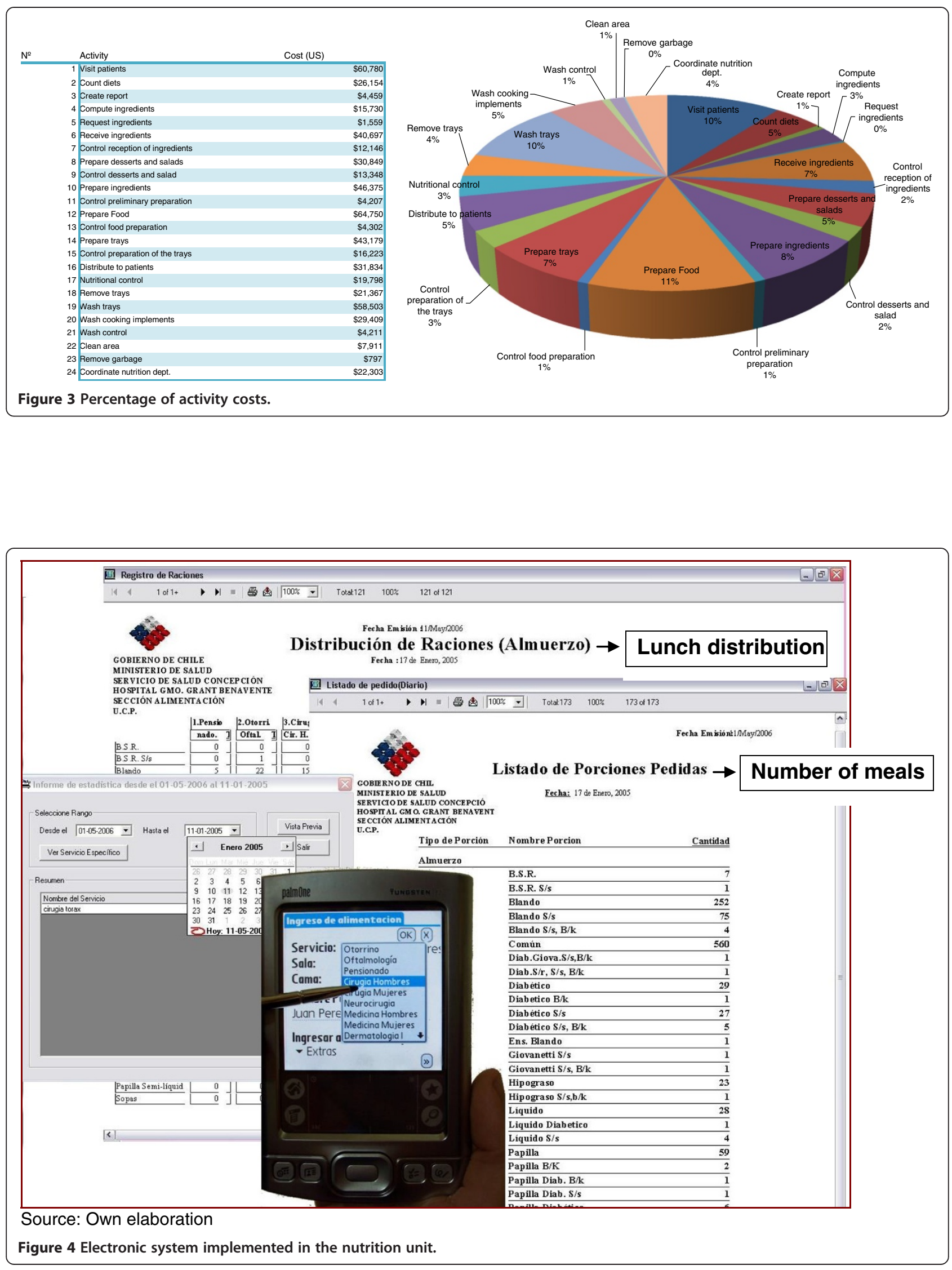


\section{Conclusion}

Many ABC models for health care institutions exist in the literature; in surgery departments [28], nursing administration [29], radiology department [18,30], nuclear medicine [31], prenatal care [32], renal dialysis clinic [33] and intensive care unit [34], among others. The cost objects may be a disease, a homogeneous group of patients, a medical procedure, etc. However, there are no costing models for a nutrition unit. The importance of the nutrition area is sometimes forgotten and differs from hospital to hospital as far as the activities and cost objects are concerned.

This study also adds evidence that the ABC methodology can be implemented in a hospital. There are hospitals that are reluctant to use $A B C$ because they believe that it is expensive and difficult to implement, that managers are not committed to such initiatives, and that the information is not fully leveraged in activity based systems [35]. However, this paper provides a replicable model for other nutrition departments that can be extended to the whole hospital.

$\mathrm{ABC}$ represents an opportunity to obtain a more detailed and rigorous method to allocate the costs for a nutrition unit. The results from this study yield a dollar amount per meal for a patient. This study, in fact, accomplished a series of objectives. First, $\mathrm{ABC}$ allows the identification of the processes and activities related with the food service of a hospital, which will help the management of the unit to understand their activities and resources. Second, there is a high level of information about the different meals produced in the hospital and their costs, which benefits the decision-making process of the services. This information was not available before. Third, there is a better understanding of what activities add value to the process of food production and delivery of the services. Fourth, it also allows one to determine the cost of activities, which are not directly related to nutritional activities, such as activities done for administrative purposes. Fifth, it provides useful information about the types and quantity of resources used and identifies possible sources of cost reduction, while maintaining the quality of services provided. Finally, a model for calculating indirect costs based on ABC can provide a stable basis for making managerial decisions in the nutrition unit and also meet the food standards that the Ministry of Health requires.

\section{Abbreviations \\ ABC: Activity based costing; ABM: Activity based management.}

\section{Competing interests}

The authors declare that they have no competing interests.

\section{Authors' contributions}

$\mathrm{LN}$ participated in the conception and the design of the project, obtained funding for the study, carried out the interpretation of the data, provided administrative, technical and material support, and reviewed the manuscript. AN participated in the conceptualization of the paper and synthesis of the literature, collected the data, carried out the analysis and interpretation of data, and drafted the manuscript. FR conceived of the study, participated in its design and coordination, developed the technological tools for the hospital, and helped to draft and review the manuscript. All authors read and approved the final manuscript.

\section{Authors' information}

LN is an assistant professor and chair of the Department of Management Control and Information Systems at University of Chile. She has a Bachelor Degree in Business from the School of Economics and Business at University of Chile, in Chile, and a PhD. in Economics and Business from Universidad Autónoma de Madrid, in Spain. Her research interests are in process innovation in health care and management control systems. She has developed and teaches several undergraduate and graduate courses in management such as Management Control and Management in Complex Organizations.

AN is an assistant professor in the Department of Management Control and Information Systems at University of Chile. She completed BA Information Systems and Management Control, BA Accounting Auditor, and Master in Finance in the School of Economics and Business at University of Chile, in Chile. She recently received a PhD in Public Health from Oregon State University Department of Public Health in Corvallis, Oregon. Her research interests are in evaluating equity and efficiency in health care services and system finance, comparing health care systems, management in health care organizations and health care policy. She has developed and teaches several undergraduate and graduate courses in management and international health, including Costs and Budgeting, Management in Complex

Organizations, Health Systems Organization, and Health Care Economics. FR is a professor at the Department of Industrial Engineering, University of Bio-Bio in Concepcion, Chile. He received a Bachelor of Mechanical Engineering from U. of Concepcion, Chile. M.Sc. and Ph.D IE from the Georgia Institute of Technology, U.S.A. His research interests are in healthcare simulation, developing objects to facilitate the development of simulation studies by non-simulation experts, which includes simulating all the different departments or services within a hospital, and process innovation. He has developed and teaches several undergraduate and graduate courses in simulation and optimization tools.

\section{Acknowledgment}

This research was supported by a FONDEF research grant (Award Number D04l1168). We also acknowledge the Guillermo Grant Benavente Hospital that granted access to all the required information and gave us permission to carry out this study.

\section{Author details}

${ }^{1}$ Department of Management Control and Information Systems, School of Economics and Business, Universidad de Chile, Santiago, Chile. ${ }^{2}$ Department of Industrial Engineering, Center of Advanced Studies in Process Simulation, Universidad del Bío Bío, Concepción, Chile.

Received: 13 March 2014 Accepted: 20 October 2014

Published online: 13 November 2014

\section{References}

1. Kisa A, Yilmaz F, Younis MZ, Kavuncubasi S, Ersoy K, Rivers PA: Delayed use of healthcare services among the urban poor in Turkey. Educ Bus Soc Contemp Middle E Issues 2009, 2(3):232-240.

2. Teke K, Kisa A, Demir C, Ersoy K: Appropriateness of admission and length of stay in a Turkish military hospital. J Med Syst 2004, 28(6):653-663.

3. Huang-Ti N-CSW, Veith I: Huang Ti Nei Ching Su Wen: The Yellow Emperor's Classic of Internal Medicine. Berkeley and Los Angeles: University of California Press; 1966.

4. Cardello A: Hospital Patient Feeding Systems. Washington, DC: National Academic Press; 1982

5. MCWhirter JP, Pennington CR: Incidence and recognition of malnutrition in hospital. BMJ 1994, 308(6934):945-948.

6. Mowe M, Bosaeus I, Rasmussen HHJ, Kondrup J, Unosson M, Irtun O: Nutritional routines and attitudes among doctors and nurses in Scandinavia: a questionnaire based survey. Clin Nutr 2006, 25(3):524-532.

7. Hartwell HJ, Edwards JSA, Symonds C: Foodservice in hospital: development of a theoretical model for patient experience and 
satisfaction using one hospital in the UK National Health Service as a case study. Journal of Foodservice 2006, 17(5-6):226-238.

8. Hartwell HJ, Edwards JSA, Beavis J: Plate versus bulk trolley food service in a hospital: comparison of patients satisfaction. Nutrition 2007, 23(3):211-218.

9. Monge $P$ : The importance of activity-based methods in radiology and the technology that now makes this possible. Radiol Manag 2006, 28(3):52-55.

10. Player S: Activity-based analyses lead to better decision making. Healthc Financ Manag 1998, 52(8):66-70.

11. Adam T, Koopmanschap MA, Evans DB: Cost-effectiveness analysis: can we reduce variability in costing methods? Int J Technol Assess Health Care 2003, 19(2):407-420.

12. Baker J: Activity-Based Costing and Activity-Based Management for Health Care. Gaithersburg, Md: Aspen Publishers; 1998.

13. Kaplan RS, Cooper R: Cost \& Effect: Using Integrated Cost Systems to Drive Profitability and Performance. Boston: Harvard Business School Press; 1998.

14. Álvarez J, Monereo S, Ortiz P, Salido C: Gestión en Nutrición Clínica. Nutr Hosp 2004, 19(3):125-134.

15. Barros $\mathrm{M}$, Pradas $\mathrm{G}$, Villar J: Costes evitables y eficiencia económica en cirugía cardíaca. Revista de Administración Sanitaria Siglo XXI 2005, 3(2):347-360.

16. Ross TK: Analyzing health care operations using ABC. J Health Care Finance 2004, 30(3):1-20.

17. Udpa S: Activity cost analysis: a tool to cost medical services and improved quality of care. Manag Care Q 2001, 9(3):34-41.

18. Laurila J, Suramo I, Brommels M, Tolppanen EM, Koivukangas P, Lanning P, Standertskjöld-Nordenstam G: Activity-based costing in radiology. Application in a pediatric radiological unit. Acta Radiológica 2000, 41(2):189-195.

19. Roybal H, Baxendale SJ, Gupta M: Using activity-based costing and theory of constraints to guide continuous improvement in managed care. Manag Care Q 1999, 7(1):1-10.

20. Dodson GM, Sinclair VG, Miller M, Charping C, Johnson B, Black M: Determining cost drivers for pediatric home health services. Nurs Econ 1998, 16(5):263-271.

21. Canby JB: Applying activity-based costing to healthcare settings. Healthc Financ Manag 1995, 49(2):50-55.

22. Carr LP: Unbundling the cost of hospitalization. Manag Account 1993, 75(5):43-48

23. Smith $\mathrm{PE}$, Smith $\mathrm{AE}$ : High-quality nutritional interventions reduce costs. Healthc Financ Manag 1997, 51(8):66-69.

24. Hedberg AM, Lairson D, Aday LA, Chow J, Suki R, Houston S, Wolf J: Economic implications of an early postoperative enteral feeding protocol. J Am Diet Assoc 1999, 99(7):802-807.

25. Brugler $L$, Bernstein $L: A n$ acuity based clinical nutrition staffing model improves acute care clinical effectiveness and maintains program viability in a managed care environment. J Am Diet Assoc 1998, 98(9):A23.

26. Pereira C: Cost-management methodology of a hospital nutrition and diet unit: a case study. O Mundo da Saúde 2004, 28(2):188-198.

27. Ferrada E: Desarrollo del Sistema ABC para el Servicio de Alimentación del Hospital Guillermo Grant Benavente. Tesis de Pregrado. Universidad del Bío Bío; 2006

28. Neriz $L$, Junge A, Ramis F: Costos basados en actividades: una aplicación a prestaciones de cirugía. Revista Administración en Salud 2006, 47(18):10-21.

29. Storjjell $\mathrm{L}$, Jessup $S$ : Bridging the gap between finance and clinical operations with activity-based cost management. J Nurs Adm 1996, 26(12):12-17.

30. Neriz L, Ramis F: Tools to Improve the Patient's Processes at Imaging Centers, Medical Imaging. Dr. Okechukwu Felix Erondu (Ed.). ISBN: 978-953-307-774-1, InTech, doi:10.5772/29111. Available from: http://www.intechopen.com/ books/medical-imaging/tools-to-improve-the-patient-s-processes-at-imaging-centers; 2011

31. Suthummanon S, Omachonu VK, Akcin M: Applying activity-based costing to the nuclear medicine unit. Health Serv Manag Res 2005, 18(3):141-150.

32. Gesse T, Golembeski S, Potter J: Cost analysis of prenatal care using the activity-based costing model: a pilot study. J Perinat Educ 1999, 8(2):20-27.

33. West TD, West DA: Applying ABC to healthcare. Manag Account 1997, 78(8):22-33.

34. Cao P, Toyabe $S$, Akazawa K: Development of a practical costing method for hospitals. Tohoku J Exp Med 2006, 208(3):213-224.

35. Lawson R: The use of activity based costing in the healthcare industry: 1994 vs 2004. Res Healthc Financ Manag 2005, 10(1):77-95.

doi:10.1186/s12913-014-0542-0

Cite this article as: Neriz et al:: A cost management model for hospital food and nutrition in a public hospital. BMC Health Services Research 2014 14:542.

\section{Submit your next manuscript to BioMed Central and take full advantage of:}

- Convenient online submission

- Thorough peer review

- No space constraints or color figure charges

- Immediate publication on acceptance

- Inclusion in PubMed, CAS, Scopus and Google Scholar

- Research which is freely available for redistribution 